\title{
E-learning bibliometric analysis from 2015 to 2020
}

\author{
Essohanam Djeki ${ }^{1}$ - Jules Dégila ${ }^{1}$ (D) Carlyna Bondiombouy ${ }^{1}$ (D) \\ Muhtar Hanif Alhassan ${ }^{2}$
}

Received: 6 May 2021 / Revised: 26 July 2021 / Accepted: 23 December 2021 /

Published online: 30 January 2022

(C) Beijing Normal University 2021

\begin{abstract}
This study aims to comprehensively examine the e-learning research field by conducting a bibliometric analysis of 12,272 publications between 2015 and 2020 from the WoS database. The study aims to highlight collaborations between authors, universities, and countries in the field, to identify the most influential authors, universities, countries, and reference papers; to know the research topics on which researchers have been working in recent years, and to examine African contribution in the field. The findings showed that the USA, Spain, England, and China are the most productive countries on e-learning. A. Tarhini is the most influential author, and e-Learning researchers host Universities are mainly from the UK, USA, and China. Computers in Human Behavior, Computers \& Education, and International Journal of Emerging Technologies in Learning are the most represented journals; Islamic Azad University, Universidade Nova de Lisboa, and King Abdulaziz University are the most influential universities. The analysis shows that the collaboration between authors, universities, and countries working on e-learning is low, and COVID-19 has a significant impact on e-learning. African contribution and research on e-learning and its security are feeble.
\end{abstract}

Essohanam Djeki

essohanam.djeki@imsp-uac.org

Jules Dégila

jules.degila@imsp-uac.org

Carlyna Bondiombouy

lynapaule@gmail.com

Muhtar Hanif Alhassan

malhassan@noun.edu.ng

1 Institute of Mathematics and Physics (IMSP) of University of Abomey-Calavi, 01 B.P: 613, Porto-Novo, Benin

2 National Open University of Nigeria, Abuja, Nigeria 
Keywords Bibliometric analysis $\cdot$ Meta-analysis $\cdot$ E-learning $\cdot$ E-learning metaanalysis $\cdot$ E-learning analysis

\section{Introduction}

Education is profoundly impacted by the progressive introduction of information and communication technology (ICT), resulting in the design and build of e-learning, or smart learning environments (SLEs) on a global scale for educational technology (Alajmi et al., 2020). With the advent of COVID-19, educational institutions are obliged to offer courses or training at a distance (Dhawan, 2020; Hoq, 2020). For some institutions, it will be a matter of improving their systems. For others, it will consist of setting up systems that allow them to offer online training to their students locked in their residences.

E-learning, as electronic learning, uses modern multimedia Internet technologies to enhance the learning experience, or quality of learning by providing learners with easy access to resources and services on the one hand, and by facilitating remote exchanges and collaboration on the other hand. The terms mobile learning (m-learning), distance learning (d-learning), online learning, remote learning, online training, distance training, digital learning are sometimes used to describe e-learning. However, there is a difference between these concepts as Basak et al. (2018) mentions by giving the nuance between E-learning, M-learning and D-learning, Moore et al. (2011) also provide the difference between e-learning, online learning, and distance learning environments.

The academic and professional literature on e-learning has grown considerably in recent years (Huynh et al., 2020). A variety of topics and issues have been explored and discussed in various studies. Research on e-learning reaches across disciplines, including education, computer science, sociology, psychology, and management, demonstrating the field's multidisciplinary nature (Cheng et al., 2014). E-learning researchers come from many disciplines and work on many different topics. And every researcher, new and old, needs to know what the research trend is, which journal publishes more publications in the field, which countries and universities are involved in the research, which are the most influential papers that should be read, which are the best collaborations between countries, universities or researchers, which are the reference researchers that should be followed, what is the evolution of the field over the years. A thematic overview of related studies is necessary for a comprehensive understanding of this large and diversified research field. Our study adopted a bibliometric approach to analyze relevant scientific publications published between 2015 and 2020, to uncover the main research themes and influential entities of the field.

The following sections are as follows: related works, research methodology, data analysis, interpretation of the results obtained, followed by a discussion of the results and a conclusion. 


\section{Related works}

Tibaná-Herrera et al. (2018a) performed a meta-analysis on the production of publications in e-learning between 2003 and 2015 using SCOPUS to identify the evolution of publications concerning e-learning. Their analysis showed that the journal "Social Science" produces many publications, and that the production of the journal "Computer Science" has unfortunately decreased considerably. The results obtained by Tibaná-Herrera et al., (2018a, 2018b) show that the research on e-learning is on the decrease, since the increase offered by the "Social Sciences" is not enough to compensate the decline in the contribution of "Computer Science." Their study contributes to the description of e-learning, in its nature and dynamics of growth in the Social Sciences, and the behavior of related knowledge domains. Their work was limited to explaining the behavior or evolution of scientific production in e-learning from bibliographic metadata.

In September 2018, Tibaná-Herrera et al. (2018b) analyzed 39,244 documents indexed in Scopus and SCImago Institutional Rankings between 2003 and 2016. Their analysis showed that the United States produces most of the research at the country level, and generates the largest number of publications, and the most significant international collaboration. At the institutional level, the University of Hong Kong is the most productive, and the National Taiwan University of Science and Technology is the most collaborative. The authors highlighted extensive collaboration at the national and institutional level, which has facilitated a $56 \%$ increase in scientific output in this area over the past five years. Their result reveals the consolidation of four clusters directly related to the development of e-learning: North America, Western Europe, Australia, and Taiwan.

Based on 108 articles, Chen et al., (2020a, 2020b) conducted a bibliometric analysis of the journal Smart Learning Environments (SLE) articles to obtain an in-depth examination of the status and trends of SLE research from 2014 to 2019. SLE articles' trend analysis indicated that the annual SLE article number had grown from 7 to 29. The "learning environment," "smart learning environment," "learning process," and "learning analytics" were the most frequently used key phrases. The most prolific countries in the field of "Smart Learning" are the USA, Canada, China, Taiwan, and Turkey; and the most prolific universities are the University of North Texas (USA), Athabasca University (Canada), Beijing Normal University (China), Hacettepe University (Turkey), and National Sun Yat-Sen University (Taiwan).

Chen et al. (2021) conducted a study to thoroughly examine the research area of smart learning by performing a thematic modeling analysis of 555 publications on smart learning collected in the Scopus database, an extension of the research of Chen et al., (2020a, 2020b). Their study to learn about influencers in the smart learning field revealed that China is the most productive country, and Tsinghua University is the most productive institution for publishing research on smart learning. The predominant research topics include mobile learning, blended learning for smart learning, IoT and cloud computing, ecosystem and ambient intelligence, and MOOCs and course content management. 
A total of 5167 publications were analyzed by Goksu (2021) in September 2019 on "mobile learning" using metadata from WoS. As a result of the bibliometric analysis, it was concluded that the most active countries in mobile learning are Taiwan, the USA, China and England. According to the keyword co-occurrence analysis, mobile devices, higher education, mobile technologies, tablets and smartphones stand out in the field of mobile learning. During the 2015-2019 period, the trending topics overall were educational technologies and, more specifically, tablets, cell phones, MOOCs, and learning strategies. It was found that Hwang is the most influential researcher, and the National Taiwan University of Science and Technology is the most influential. According to the analyses conducted in journals, "Computers \& Education," "British Journal of Educational Technology," and "Educational Technology \& Society" are the most contributing journals. In addition to the parameters such as citation and TLS calculated using VoSViewer and Scimat, the author also used the h-index for ranking the influential entities using Harzing's Publish and Perish's software.

Cheng et al. (2014) conducted a bibliometric analysis on e-learning at the workplace on research published between 2000 and 2012 by examining 324 articles published in academic journals and conference proceedings. Their results identify six research themes in the field, which are then classified into four dimensions. The themes are e-learning for continuing education and professional development, e-learning in healthcare, using social media for e-learning, and integrating knowledge management with e-learning. The four dimensions highlighted by the authors are e-learning for continuing education and professional development, e-learning in the health care sector (as one of the most prolific e-learning initiatives), the use of social media for learning, and the integration of knowledge management into e-learning.

In order to have a comprehensive overview of "Classroom dialogue," Song et al. (2019) conducted a bibliometric analysis on 3914 papers published between 1999 and 2018 retrieved from the WoS database. The authors' results show that publications and citations related to classroom dialogue have increased significantly over the past 20 years, and that the USA has contributed spectacularly to the increase in publications, especially since 2012. Computers \& Education, and Journal of Research in Science Teaching are the two most prestigious journals according to (Song et al., 2019). Thematic characteristics related to classroom dialogue research were revealed through keyword analysis. Several frequent keywords were identified by authors throughout the period, e.g., "classroom," "discourse," "student") and, at the parallel, new keywords emerged such as "technology," "computer-mediated communication," which reflect changing trends in the field.

On the celebration of the 50th anniversary of the British Journal of Educational Technology (BJET), Chen et al., (2020a, 2020b) conducted a bibliometric analysis in order to see an overview of the impact of the journal in its domain. For this purpose, they performed a bibliometric analysis of the 3710 publications of this journal from 1971 to 2018 as indexed in the Web of Science. UK, USA, Australia, Taiwan, and Canada are the most prolific country according to h-index value, citations and number of publications. Their findings highlighted several research hotspots and emerging topics such as technology-enhanced classroom 
pedagogy, blended learning, online social communities, mobile-assisted language learning, game-based learning, and socialized online learning. Based on the authors' research findings, BJET has played an increasingly important role in the field of educational technology, and it will continue to play a leading role in this field in the future (Chen et al., 2020a, 2020b).

Chen et al. (2019) carried out a study analyzing the status and trends of research in educational technology to get a comprehensive review of articles on educational technology over the last 40 years. Their study is a bibliometric analysis of research topics, author profiles, and collaboration networks using a leading journal, Computers \& Education. The authors used the WoS database, retrieving 3,963 articles published by the journal during the period 1978-2018. The yearly distribution of articles shows a meaningful growth of the journal's publications, especially between 2005 and 2011. The analysis of the evolution of keywords highlights some predominant topics such as "interactive learning environment," "teaching/learning strategies," "pedagogical issue," and "improving classroom teaching."

\section{Research methodology}

\section{Research aim}

When investigating "e-learning" in the literature, we can notice a considerable amount of research conducted by the scientific community on the subject. By examining the literature closely, we notice that there are bibliometric analyses or literature reviews on "e-learning". All these studies show that research on "e-learning" has increased over the years. This means that "e-learning" is an exciting, important and promising field, especially with the arrival of COVID-19 where we are experiencing lockdown or quarantine. The only way to reduce the virus's spread while still pursuing studies is through distance learning or online training.

Although there are a significant number of studies on "e-learning," or "mobile learning," or "online learning," or "distance learning," none are conducted on bibliometric analysis or meta-analysis in recent years. This paper aims to perform a meta-analysis of the "e-learning" research work from 2015 to 2020 using bibliometric metadata. The field analysis will be done according to variables such as keywords, authors, countries, citations, publications, universities, and journals. It will be a question of knowing:

1. What is the co-authorship's status?

2. Who are the most influential authors?

3. Which are the most influential publications?

4. Which are the most influential journals?

5. Which are the most influential countries and universities? 
6. What is keywords' distribution and trend?

7. What is the African countries' contribution on "e-learning" researches?

\section{Research design}

This study is carried out according to an approach of analysis of bibliometric data of scientific publications dealing with "e-learning". The analysis focuses on two parts: (1) bibliometric mapping to examine the trends in e-learning, and (2) analysis of keywords indexed in the articles to identify research groups and to understand the research themes associated with e-learning.

\section{Obtaining data set}

To perform our study, the bibliographic database Web of Science (WoS) was used for its coverage and peer review of its indexed publications (Birkle et al., 2020). WoS was used to extract a representative set of relevant literature using the keyword "e-learning", covering 2015 to 2020 from Web of Science Core Collection. The following search query was constructed and applied in the database: TOPIC: ("e-learning") Timespan: 2015-2020. Indexes: SCI-EXPANDED, SSCI, A\&HCI, CPCI-S, CPCI-SSH, BKCI-S, BKCI-SSH, ESCI, CCR-EXPANDED, IC. WoS was consulted on March 12, 2021, and a total of 12,272 publications were obtained. The data set we used, consists of 25 different ".txt" files since WoS allows downloading up to 500 records simultaneously.

\section{Data analysis}

Analyses of co-authorship, bibliographic coupling, keyword co-occurrence, and citation were performed on bibliometric meta-data using VOSViewer software. For bibliographic coupling, the relationships of elements such as publications, journals and authors. are determined according to the number of shared resources, i.e., a reference to the same publication in two different sources is considered bibliographic coupling. The analysis of the co-occurrence of keywords reveals the evolution of the domain over time (Deng \& Xia, 2020). It is therefore an efficient method to identify hot topics in a given research domain. Citation analysis helps researchers to detect popular research topics and papers that other researchers work on (Lai, 2020). The results of the analysis are presented in the form of a table or network visualization map.

Figure 1 shows the number of e-learning publications published each year between 2015 and 2020. Figure show that research on e-learning is significant and relatively stable, ranging from 2244 (2015) to 2265 (2016). There were 2244 articles published in 2015, representing $18.286 \%$ of publications; 2265 publications in 2016, representing $18.457 \%$; 2,116 publications in 2017, representing $17.243 \%$; 2078 publications in 2018, representing $16.933 \%$; 2,010 publications in 2019, representing $16.379 \%$ of publications, and 1559 publications in 2020, representing $12.704 \%$ of publications. We notice that, more articles were published in 2015 and 2016, and 


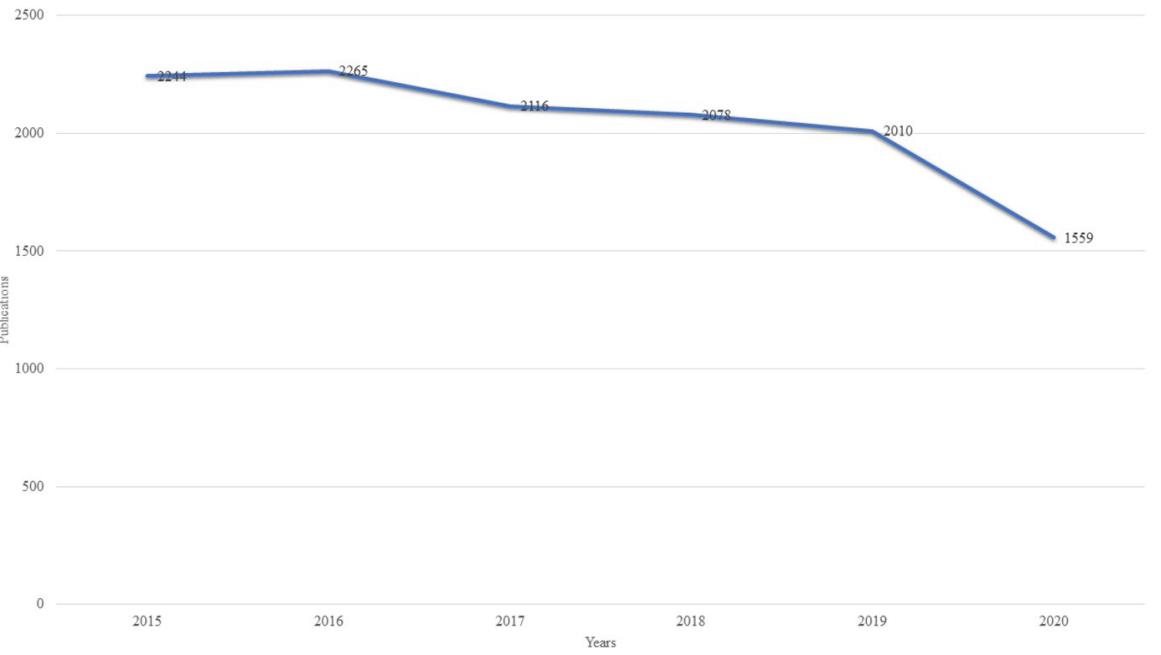

Fig. 1 Publication on e-learning research according to years

less in 2020, the year in which we expected to have more publications on e-learning as it was one of the solutions to ensure the continuity of learning during COVID-19. Furthermore, we can observe that the number of publications decreases over time.

It was found with the analysis of the data set that the publications related to e-learning cover 151 countries, mainly Spain (8.263\%), USA (7.456\%), England (5.566\%), China (5.231\%), Romania (4.824\%), Germany (4.759\%), India (4.685\%), Russia (4.278\%), Italy (3.251\%), etc. as we can see on Fig. 2. The analysis also reveals that the publications were written in 24 languages, of which $95.013 \%$ in

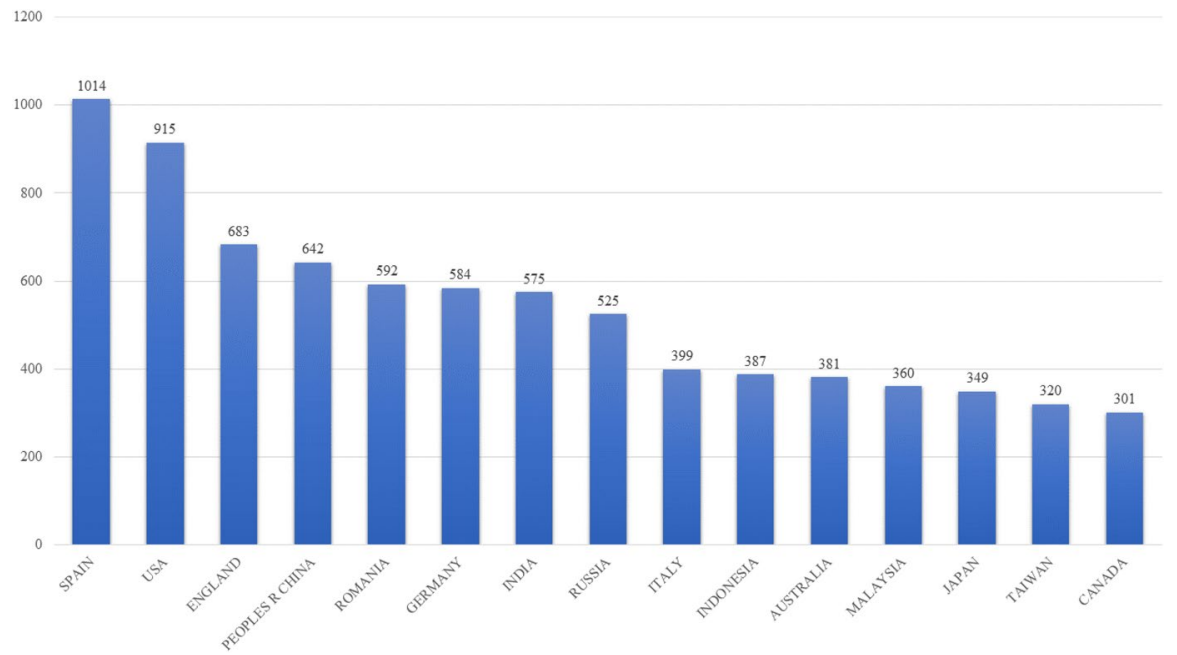

Fig. 2 Publication on e-learning research according to countries 


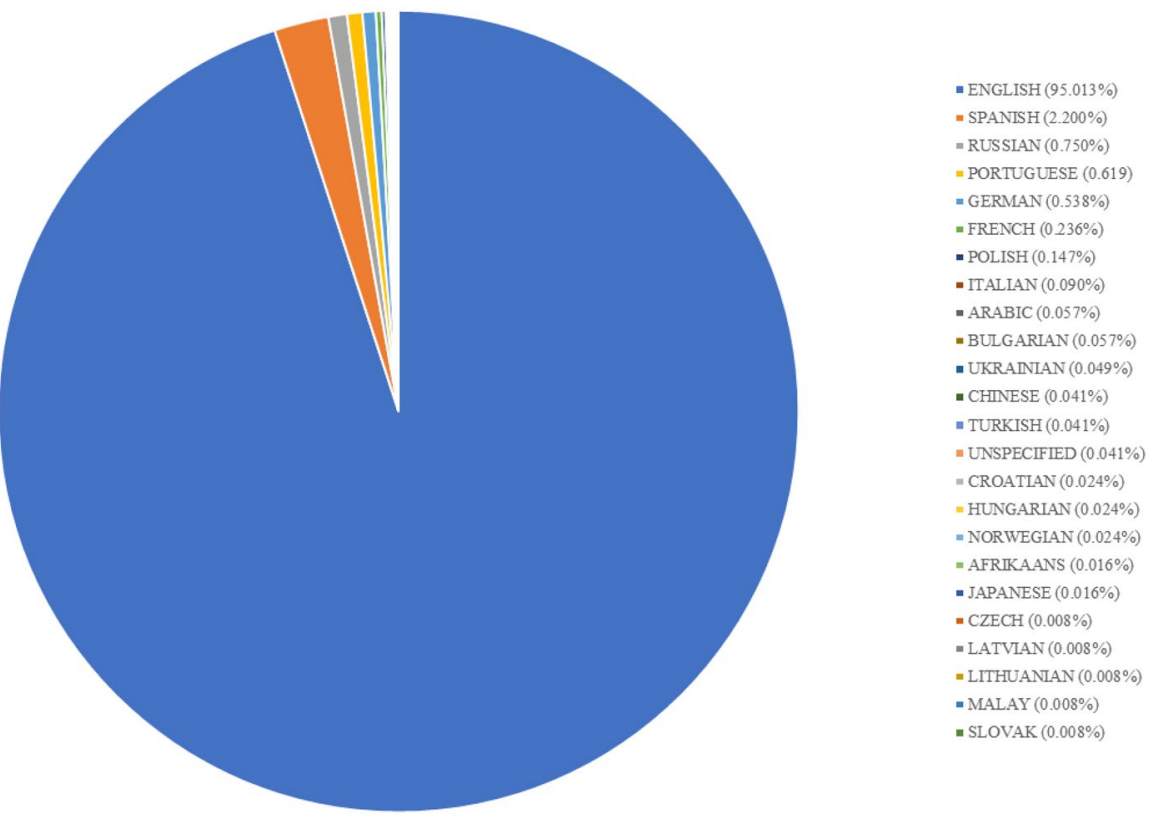

Fig. 3 Publication on e-learning research according to languages

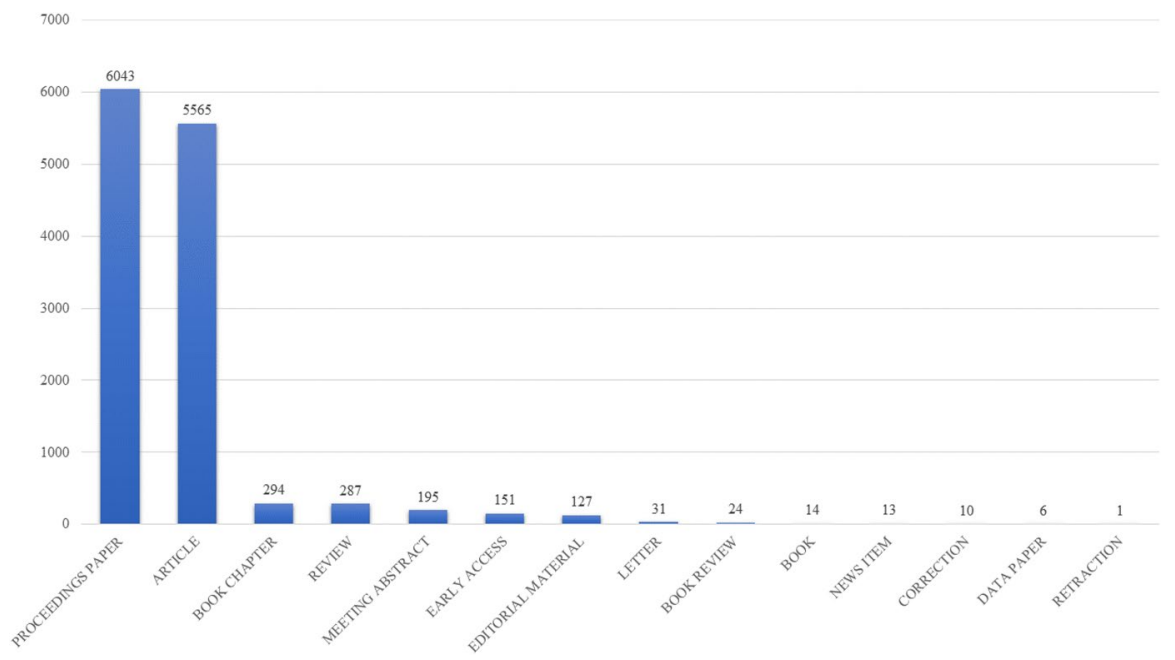

Fig. 4 Publication on e-learning according to document type

English (11,660 publications), 2.200\% in Spanish (270 publications), $0.750 \%$ in Russian (92 publications), $0.619 \%$ in Portuguese (76 publications), $0.538 \%$ in German (66 publications), $0.236 \%$ in French (29 publications), $0.147 \%$ in polish (18 publications), $0.090 \%$ in Italian (11 publications) as we can see on Fig. 3. 
Figure 4 shows the types of papers published on e-learning between 2015 and 2020. We notice that 49.242\% are "Proceedings Paper" (6043 publications), $45.347 \%$ of the publications are "Article" (5565 publications), 2.396\% are "Book Chapter" (294 publications), 2.339\% are "Review" (287 publications), 1.589\% are "Meeting Abstract", i.e., 195 publications. Figure 5 shows the areas of research that are interested in e-learning. Among these areas, we have mainly "Education Educational Research" which produced 5948 publications out of 12,272 publications, i.e., 48.468\% of the publications between 2015 and 2020; "Computer Science" which produced 3632 publications (29.596\%); "Engineering" produced 1692 publications (13.787\%); "Telecommunications" published 456 publications (3.716\%); "Economic Business" published 447 publications (3.642\%).

Regarding the organizations, institutions or universities that provide a great work on e-learning, we have mainly "UNIV POLITEHN BUCURESTI" (University Politehnica of Bucharest from Romania) 115 publications, i.e., 0.937\%; "UNIV HRADEC KRALOVE" (University of Hradec Kralove from Czech Republic) with 66 publications, i.e., 0.538\%; "UNIV HONG KONG" (University of Hong Kong) 57 publications, i.e., 0.464\%; "KING ABDULAZIZ UNIV” (King Abdulaziz University from Saudi Arabia) with 53 publications, i.e., 0.432\%; "UNIV COMPLUTENSE MADRID" (Complutense University of Madrid from Spain) with 52 publications, i.e., 0.424\% (see Fig. 6).

C. Radu published 28 publications $(0.228 \%)$, M. Virvou 27 publications $(0.220 \%)$, S. Lujan-Mora 25 publications (0.204\%), C. Meinel 25 publications $(0.204 \%)$, I. Simonova 24 publications $(0.196 \%)$, H. B. Santoso 22 publications $(0.179 \%)$, M. Montebello 21 publications $(0.171 \%)$, C. Troussas 21 publications $(0.171 \%)$, M. Ivanovic 20 publications, i.e., $0.163 \%$ (see Fig. 7).

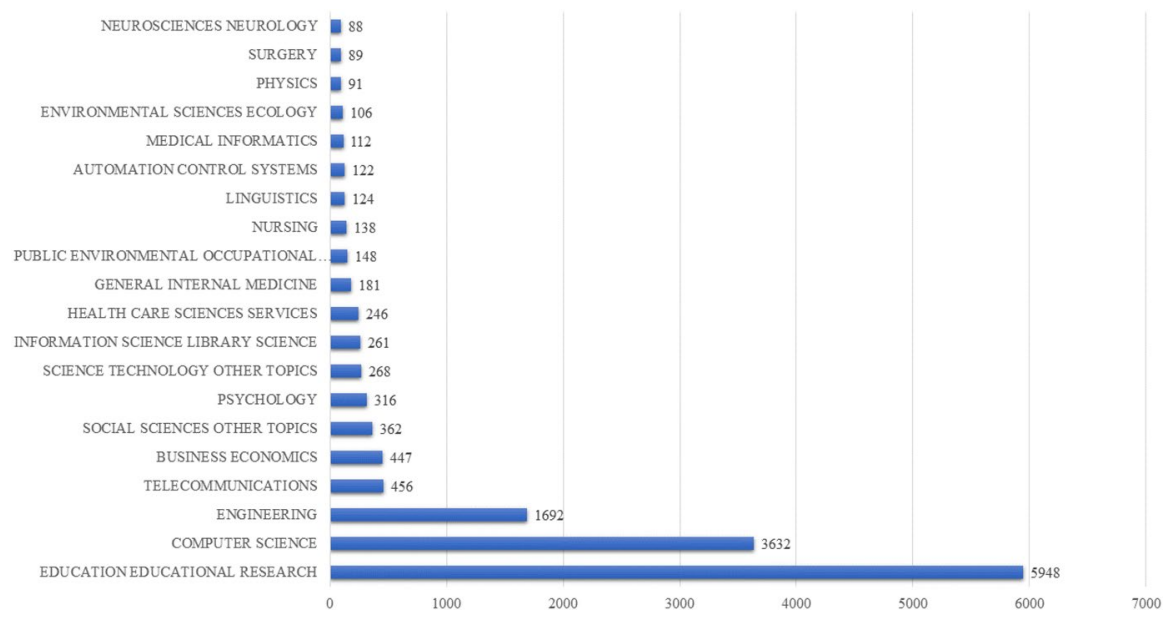

Fig. 5 Publication on e-learning according to research areas 


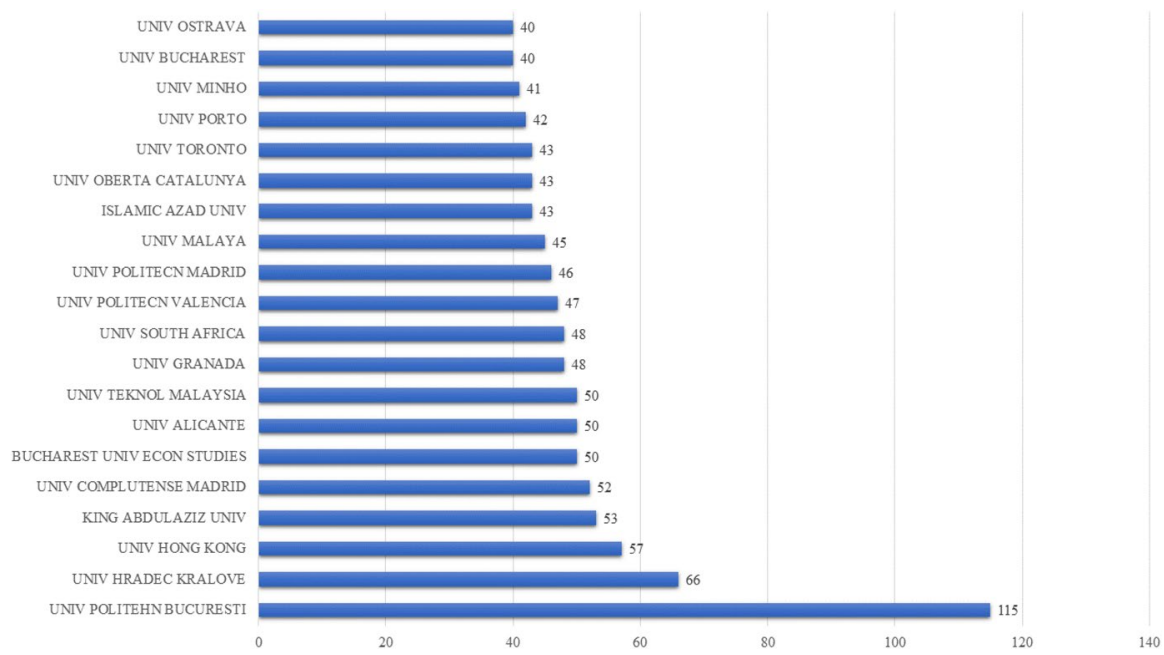

Fig. 6 Publication on e-learning according to organizations

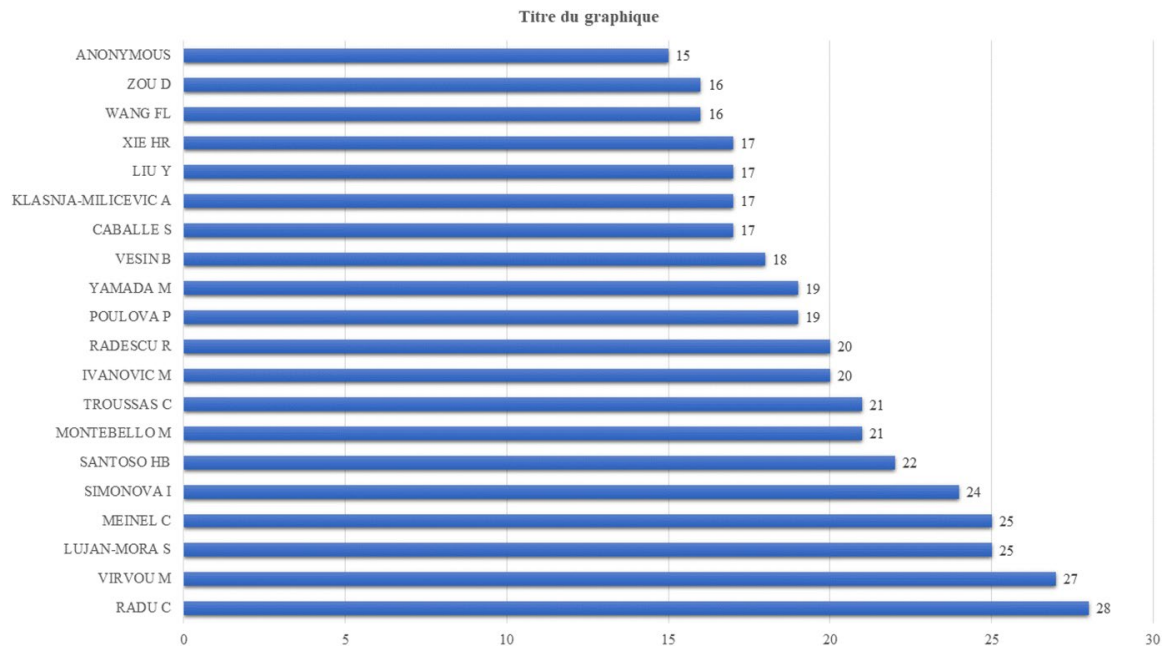

Fig. 7 Publication on e-learning according to authors

\section{Results}

\section{Co-authorship status}

For the analysis of collaboration between authors on e-learning, authors with at least 5 publications were included, which allowed us to go from 31,445 authors to 410 authors. The analysis revealed 211 different groups (see Fig. 8), in which only 3 groups were connected (see Fig. 9), and a few researchers provided this 


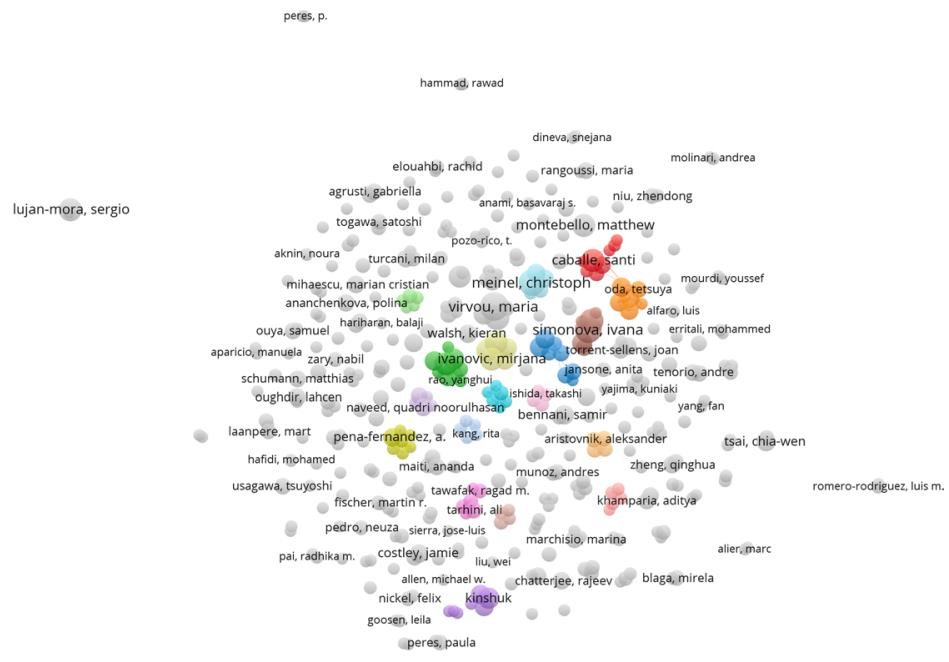

santoso, harry budi

\& vosviewer

Fig. 8 Co-authorship network map in e-learning
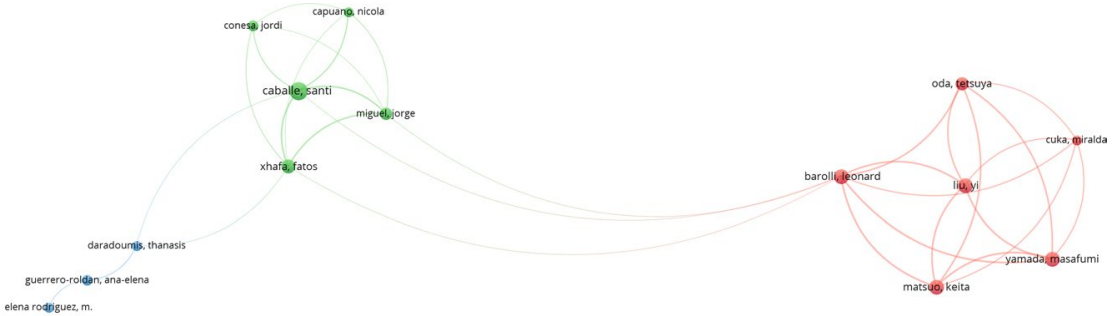

Fig. 9 Co-authorship connected clusters map in e-learning

connection. As shown in Fig. 8, the relevant cooperative author groups are presented in different colors and represent the focus of e-learning research. When we examine the co-authorship network visualization map in Fig. 8, we understand that the cooperation between researchers working on e-learning is low even though there are enough authors.

Also, the number of active researchers is weak in most groups. For example, out of the 211 groups, the most important groups are composed of 3 groups of 8 authors, 2 groups of 7 authors, 4 groups of 6 authors, 5 groups of 5 authors, 9 groups of 4 authors, 18 groups of 3 authors, 56 groups of 2 authors, and 110 single authors. 
The largest group is the red cluster composed of 8 authors, among which authors with more publications are S. Caballe (17 publications), F. Xhafa (10 publications), and J. Miguel (10 publications). The second group is the green one, also composed of 8 authors. The most prominent in this group are $\mathrm{H}$. Xie (17 publications), L. F. Wang (15 publications), and D. Zou (15 publications). The third-largest group is the one in blue. In this group of 8 authors, E. Smyrnova-Trybulska stands out with 13 publications, and N. Morz (12 publications).

The co-authorship analysis conducted to determine the cooperation of researchers on a country basis in e-learning, takes into account countries with more than 5 publications. This analysis revealed that only 107 countries out of 150 met this criterion and formed 11 different co-author groups. It was found that 106 other countries, except for Moldova, were connected to the network. It should be noted that among the 107 connected countries, Israel is alone in its cluster.

Figure 10 shows the countries whose authors collaborate on e-learning. The fact that the clusters showing the countries in which authors collaborate the most, is not very different from each other shows that researchers are working together on e-learning worldwide. At the end of the graph, the countries that have weak cooperation with other countries/clusters in the network, are generally developing countries. According to total link strength (TLS) value, the most influential countries in terms of collaboration are England, the USA, Spain, Italy, Germany, Australia, China, Netherlands, France, Canada, Portugal, and Belgium. Remarkably, Germany, Russia, Romania, and Italy belong to the same group. On the other hand, India and the USA also belong to the same group, and Australia and China are members of the same group.

\section{Most influential researchers}

As a result of the citation analysis, including authors with at least 5 publications, it was observed that the top 20 authors with the highest TLS value were ranked in the Table 1. It can be seen that N. Q. Naveed is the most influential author. Besides, H. Xie, D. Zou, A. Shah and N. R. Mohamed Qureshi also distinguished themselves. Usually, researchers in e-learning are those working in universities in the UK, USA, and China.

Ranked by citations, the top 10 researchers are A. Tarhini, M. Aparicio, T. Oliveira, K. J. Tarus, Z. Niu, K. Ahmed, P. Dasgupta, R. M. Fischer, and J. Luis Fernandez-Aleman (see Table 2). Furthermore, when ranked by the number of publications (Fig. 7), only few researchers are found in the top 20 ranked by TLS or citations. This result shows that although there is much research on e-learning, researchers do not reach the expected interest in this field, and that publishing more papers does not necessarily mean that an author is the most influential. We have to consider the number of citations and TLS. By combining these parameters, we can claim that A. Tarhini is the most influential author with 9 papers cited 320 times and 49 as TLS value. 


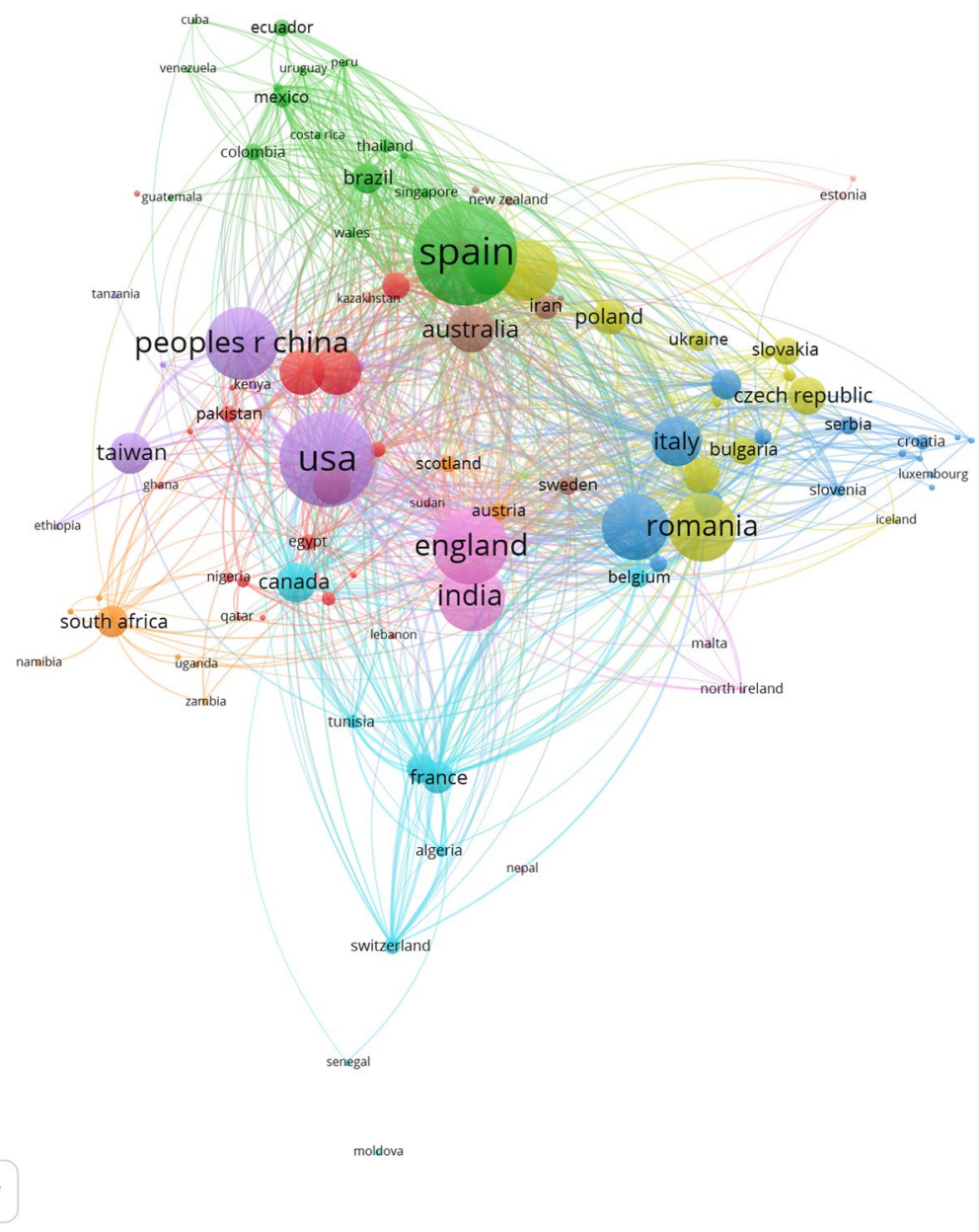

Fig. 10 The country co-authorship in e-learning

\section{Most influential papers}

From the 12272 publications analyzed, only 74 papers are cited more than 50 times. The top 15 most influential publications are presented in Table 3. The analysis of Table 3 shows that the research on e-learning focuses much more on the learner: the social aspect, the learner experience, the impact of e-learning on the learner's learning, and how to improve the learning. The article by J. Lu, et al. entitled "Recommender system application developments: A survey" published in the journal "Decision Support Systems" in 2015 is the most cited article in e-learning (468 times in WoS and 1018 times in Google Scholar). The second most cited paper is J. L. Jensen et al. entitled "Improvements from a Flipped Classroom May Simply Be the Fruits of Active Learning" also published in 2015 in the journal "CBE-Life Sciences Education," cited 255 times in WoS and 721 times in Google Scholar. The third most 
Table 1 Most influential researchers in e-learning ranked by TLS

\begin{tabular}{|c|c|c|c|c|c|}
\hline Rank & Author & Country & Papers & Cites & TLS \\
\hline 1 & N. Q. Naveed & Saudi Arabia & 10 & 63 & 85 \\
\hline 2 & H. Xie & Hong Kong & 17 & 58 & 73 \\
\hline 3 & D. Zou & Hong Kong & 15 & 52 & 72 \\
\hline 4 & A. Shah & Malaysia & 9 & 44 & 72 \\
\hline 5 & N. R. Mohamed Qureshi & Saudi Arabia & 5 & 41 & 60 \\
\hline 6 & S. Sanober & Saudi Arabia & 5 & 41 & 56 \\
\hline 7 & B. Kolodziejczak & Poland & 9 & 29 & 59 \\
\hline 8 & M. Roszak & Poland & 9 & 29 & 59 \\
\hline 9 & L. F. Wang & Hong Kong & 15 & 30 & 53 \\
\hline 10 & A. Al-Abri & Oman & 6 & 6 & 52 \\
\hline 11 & Y. Jamoussi & Oman & 6 & 6 & 52 \\
\hline 12 & N. Kraiem & Oman & 6 & 6 & 52 \\
\hline 13 & A. Tarhini & Oman & 9 & 320 & 49 \\
\hline 14 & N. Ahmad & Saudi Arabia & 5 & 19 & 47 \\
\hline 15 & K. J. Tarus & Kenya & 6 & 203 & 46 \\
\hline 16 & M. Injadat & Canada & 5 & 28 & 42 \\
\hline 17 & A. Moubayed & Canada & 5 & 28 & 42 \\
\hline 18 & A. Shami & Canada & 5 & 28 & 42 \\
\hline 19 & M. Nakazawa & Japan & 7 & 8 & 42 \\
\hline 20 & S. Hirasawa & Japan & 7 & 8 & 42 \\
\hline
\end{tabular}

cited paper is by H. Mohammadi et al. whose title is "Investigating users' perspectives on e-learning: An integration of TAM and IS success model" also published in 2015 in the journal "Computers in Human Behavior," cited 176 times in WoS and 464 times in Google Scholar.

The analysis also revealed that the most cited papers are the oldest, as most of the popular papers are published in 2015 and 2016, and the most recent in the top 15 is published in 2017. However, there is one Hot Paper, by Blake et al. whose title is "Mitigating the Psychological Impact of COVID-19 on Healthcare Workers: A Digital Learning Package" published in 2020 in the journal "International Journal of Environmental Research and Public Health," cited 58 times in WoS and 156 times in Google Scholar.

Among the most cited papers, there are some that deal with literature review, or systematic literature review, or metanalysis, which shows the importance of social and experimental research in e-learning, and therefore the importance of review studies.

\section{Most influential journals}

To determine the most influential journal that published papers on e-learning, a citation analysis was performed. Out of 4129 sources, only 177 journals/publishers 
Table 2 Most influential researchers in e-learning ranked by citation

\begin{tabular}{lllccc}
\hline Rank & Author & Country & Papers & Cites & TLS \\
\hline 1 & A. Tarhini & Oman & 9 & 320 & 49 \\
2 & M. Aparicio & Portugal & 6 & 251 & 38 \\
3 & T. Oliveira & Portugal & 5 & 249 & 38 \\
4 & J. N. Navimipour & Tehran & 5 & 244 & 12 \\
5 & K. J. Tarus & Kenya & 6 & 203 & 46 \\
6 & Z. Niu & USA & 8 & 203 & 40 \\
7 & K. Ahmed & UK & 6 & 203 & 10 \\
8 & P. Dasgupta & UK & 5 & 178 & 18 \\
9 & R. M. Fischer & Germany & 7 & 152 & 7 \\
10 & J. Luis Fernandez-Aleman & Spain & 5 & 148 & 0 \\
11 & J. F. Garcia-Penalvo & Spain & 5 & 132 & 5 \\
12 & K. Sostmann & Germany & 5 & 125 & 7 \\
13 & E. Kurilovas & Lithuania & 11 & 116 & 3 \\
14 & M. Ivanovic & Serbia & 18 & 112 & 19 \\
15 & A. Klasnja-Milicevic & Serbia & 17 & 107 & 26 \\
16 & C. W. Tsai & Taiwan & 13 & 100 & 12 \\
17 & L. De-Marcos & Spain & 7 & 99 & 29 \\
18 & A. Garcia-Cabot & Spain & 6 & 97 & 29 \\
19 & E. Garcia-Lopez & Spain & 6 & 97 & 29 \\
20 & F. Jose Garcia-Penalvo & Spain & 5 & 94 & 6 \\
\hline & & & & &
\end{tabular}

published at least 10 papers on e-learning between 2015 and 2020. Following the citation analysis, the top 20 journals with the highest TLS value are listed in Table 4, and the top 20 journals with the highest citations in Table 5.

Examining Table 4, the journal with the highest TLS value is "Computers in Human Behavior." In addition to the related journal, "Computers \& Education," "Education and Information Technologies," "International Journal of Emerging Technologies in Learning," and "IEEE Access" were the leading journals. When Table 5 is examined, the journal with the highest citations is "Computers in Human Behavior." The second journal is "Computers \& Education" again. In addition to these related journals, "BMC Medical Education," "British Journal of Educational Technology," and "International Journal of Emerging Technologies in Learning" were the leading journals.

The observation of Tables 4 and 5 reveals that "Computers in Human Behavior" is the most influential journal, followed by "Computers \& Education," and "International Journal of Emerging Technologies in Learning".

\section{Most influential countries}

To identify the most influential country in e-learning research, a citation analysis was performed considering the number of citations and the TLS value. It was found that research is being conducted on e-learning in 151 different countries. The top 20 


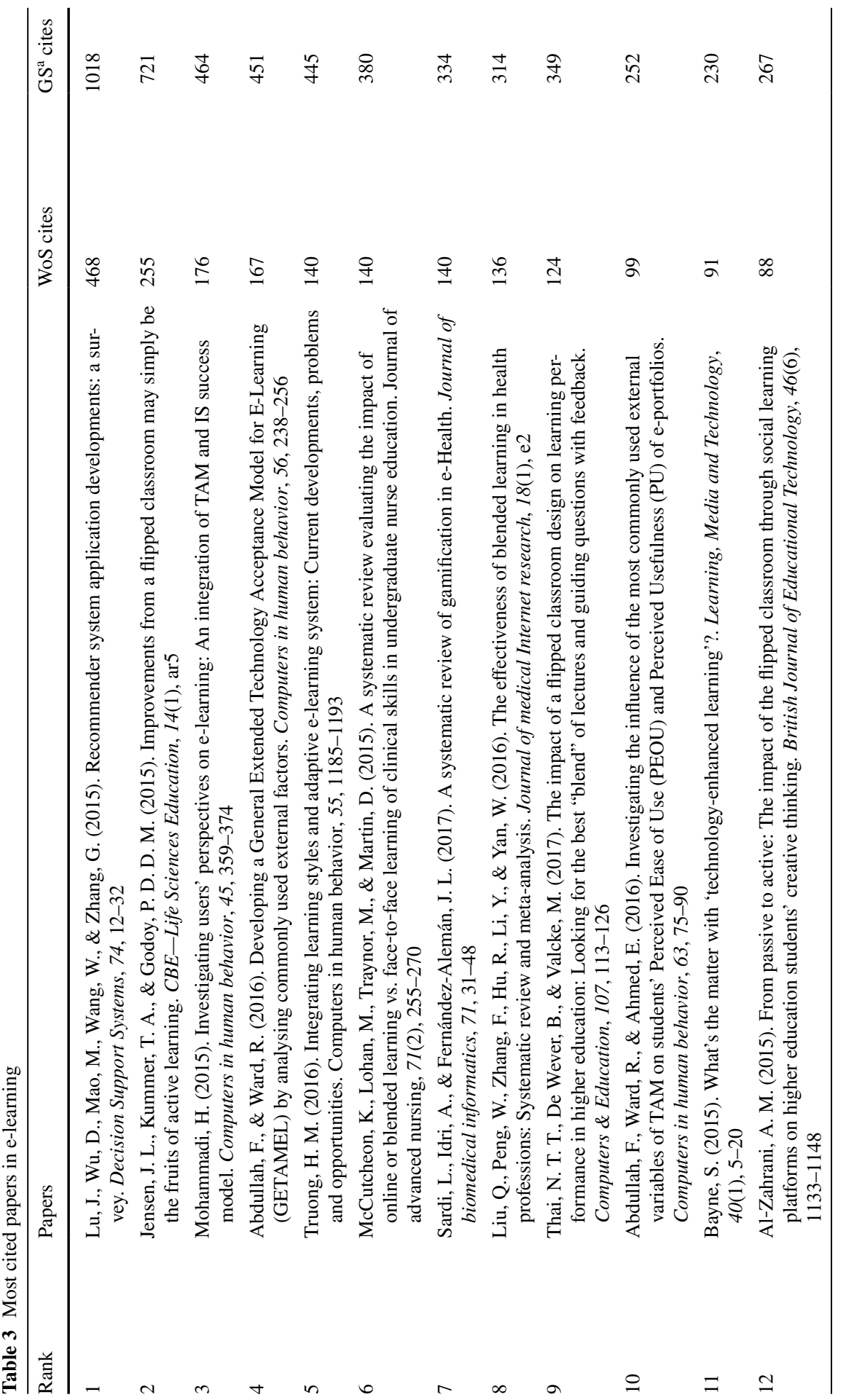




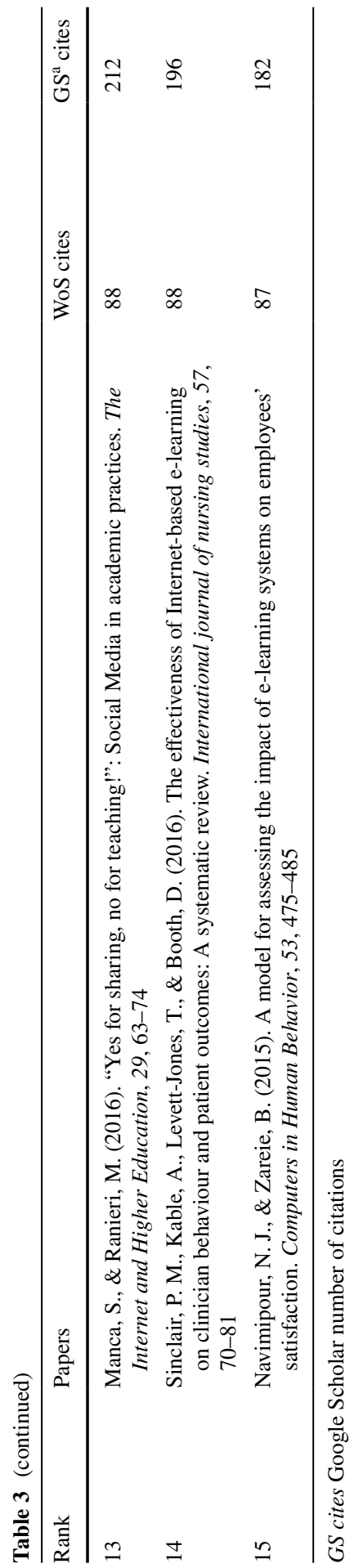


Table 4 Most influential Journal in e-learning ranked by TLS

\begin{tabular}{|c|c|c|c|c|}
\hline Rank & Journal & Papers & WoS Cites & TLS \\
\hline 1 & Computers in Human Behavior & 73 & 2284 & 434 \\
\hline 2 & Computers \& Education & 52 & 1271 & 296 \\
\hline 3 & Education and Information Technologies & 112 & 468 & 216 \\
\hline 4 & International Journal of Emerging Technologies in Learning & 175 & 594 & 195 \\
\hline 5 & IEEE Access & 58 & 323 & 175 \\
\hline 6 & Interactive Learning Environments & 52 & 485 & 151 \\
\hline 7 & International Review of Research in Open and Distributed Learning & 60 & 514 & 141 \\
\hline 8 & British Journal of Educational Technology & 44 & 623 & 118 \\
\hline 9 & BMC Medical Education & 73 & 703 & 99 \\
\hline 10 & $\begin{array}{l}\text { International Journal of Advanced Computer Science and Applica- } \\
\text { tions }\end{array}$ & 102 & 158 & 97 \\
\hline 11 & Sustainability & 45 & 144 & 89 \\
\hline 12 & Journal of Medical Internet Research & 35 & 498 & 84 \\
\hline 13 & Interactive Technology and Smart Education & 35 & 139 & 84 \\
\hline 14 & Electronic Journal of E-learning & 50 & 304 & 80 \\
\hline 15 & Journal of Information Technology Education-Research & 19 & 62 & 74 \\
\hline 16 & Turkish Online Journal of Distance Education & 65 & 86 & 73 \\
\hline 17 & Telematics and Informatics & 19 & 359 & 69 \\
\hline 18 & Educational Technology \& Society & 35 & 303 & 64 \\
\hline 19 & Plos One & 23 & 181 & 63 \\
\hline 20 & Computer Applications in Engineering Education & 52 & 231 & 59 \\
\hline
\end{tabular}

influential countries in e-learning with the highest citations in Table 6, and the top 20 influential countries with the highest TLS value are presented in Table 7.

Observing Table 6, the most cited country is the USA, followed by Spain, England, Australia, and China. However, the country with the highest TLS value is England, followed by the USA, Spain, China, and Malaysia. By considering the value of TLS and the number of citations, we can claim that the most influential countries are the USA, Spain, England, and China.

\section{Most influential universities}

More than 8757 universities/institutions have researched e-learning between 2015 and 2020. Citation analysis was performed on the 8757 universities to know which one is the most influential working on e-learning. The top 20 influential universities with the highest citations in Table 8 and the top 20 influential universities with the highest TLS value are presented in Table 9. The University of Technology of Sydney is the most cited (with the most cited papers). It is also remarkable to see that it one of the universities with few papers published in the top 20, but is nevertheless the most cited according to Table 8. Other than this university, the most cited universities are Islamic Azad University, University of Malaya, Universidade Nova de 
Table 5 Most influential Journal in e-learning ranked by citations

\begin{tabular}{llrrr}
\hline Rank & Journal & Papers & WoS Cites & TLS \\
\hline 1 & Computers in Human Behavior & 73 & 2284 & 434 \\
2 & Computers \& Education & 52 & 1271 & 296 \\
3 & BMC Medical Education & 73 & 703 & 99 \\
4 & British Journal of Educational Technology & 44 & 623 & 118 \\
5 & International Journal of Emerging Technologies in Learning & 175 & 594 & 195 \\
6 & International Review of Research in Open and Distributed Learning & 60 & 514 & 141 \\
7 & Anatomical Sciences Education & 35 & 510 & 21 \\
8 & Journal of Medical Internet Research & 35 & 498 & 84 \\
9 & Interactive Learning Environments & 52 & 485 & 151 \\
10 & Education and Information Technologies & 112 & 468 & 216 \\
11 & Telematics and Informatics & 19 & 359 & 69 \\
12 & IEEE Access & 58 & 323 & 175 \\
13 & Electronic Journal of E-learning & 50 & 304 & 80 \\
14 & Educational Technology \& Society & 35 & 303 & 64 \\
15 & Nurse Education Today & 28 & 272 & 35 \\
16 & Internet and Higher Education & 6 & 260 & 52 \\
17 & Educational Technology Research and Development & 6 & 260 & 52 \\
18 & IEEE Transactions on Learning Technologies & 29 & 233 & 39 \\
19 & Computer Applications in Engineering Education & 52 & 231 & 59 \\
20 & Medical Teacher & 28 & 205 & 46 \\
\hline & & & & \\
\hline
\end{tabular}

Lisboa, and the University of Pittsburgh. Regarding the universities with the highest TLS value, we have King Abdulaziz University in the first rank. In addition to the related university, King Khalid University, Universidade Nova de Lisboa, King Saud University, and Islamic Azad University were the leading according to Table 9.

By combining the two parameters (citations and TLS value), we can claim that Islamic Azad University, Universidade Nova de Lisboa, and King Abdulaziz University are the most influential universities.

\section{The keywords analysis and e-learning trend topics}

A total of 24843 keywords were used in 12272 publications dealing with e-learning. According to the co-occurrence analysis performed on the keywords, only 908 keywords appear in more than 10 publications. The cooccurrence analysis revealed that the keywords are grouped in 8 clusters or groups, as shown in Fig. 11. The keywords in the clusters give information about related research topics in the area of interest (Goksu, 2021).

As seen in Fig. 11, the largest cluster is the red cluster with 208 keywords. Words like learning analytics, design, system, learning management system, collaborative learning, adaptive learning, personalization, ontology, semantic web, data mining, and machine learning are highlighted. The green cluster 
Table 6 Most influential countries in e-learning ranked by citations

\begin{tabular}{|c|c|c|c|c|}
\hline Rank & Country & Documents & WoS cites & TLS \\
\hline 1 & USA & 912 & 4363 & 1215 \\
\hline 2 & Spain & 1013 & 3817 & 1185 \\
\hline 3 & England (UK) & 682 & 3803 & 1441 \\
\hline 4 & Australia & 380 & 2771 & 852 \\
\hline 5 & China & 640 & 2372 & 1021 \\
\hline 6 & Germany & 583 & 1832 & 670 \\
\hline 7 & Italy & 398 & 1616 & 644 \\
\hline 8 & Canada & 300 & 1605 & 550 \\
\hline 9 & India & 675 & 1423 & 807 \\
\hline 10 & Taiwan & 319 & 1399 & 421 \\
\hline 11 & Malaysia & 360 & 1159 & 946 \\
\hline 12 & Netherlands & 204 & 1064 & 392 \\
\hline 13 & Iran & 163 & 1056 & 530 \\
\hline 14 & Saudi Arabia & 286 & 929 & 795 \\
\hline 15 & Turkey & 187 & 883 & 485 \\
\hline 16 & Portugal & 278 & 873 & 516 \\
\hline 17 & Russia & 524 & 862 & 353 \\
\hline 18 & Brazil & 223 & 795 & 313 \\
\hline 19 & Belgium & 122 & 773 & 262 \\
\hline 20 & Romania & 591 & 674 & 326 \\
\hline
\end{tabular}

Table 7 Most influential countries in e-learning ranked by TLS

\begin{tabular}{|c|c|c|c|c|}
\hline Rank & Country & Documents & WoS cites & TLS \\
\hline 1 & England (UK) & 682 & 3803 & 1441 \\
\hline 2 & USA & 912 & 4363 & 1215 \\
\hline 3 & Spain & 1013 & 3817 & 1185 \\
\hline 4 & China & 640 & 2372 & 1021 \\
\hline 5 & Malaysia & 360 & 1159 & 946 \\
\hline 6 & Australia & 380 & 2771 & 852 \\
\hline 7 & India & 675 & 1423 & 807 \\
\hline 8 & Saudi Arabia & 286 & 929 & 795 \\
\hline 9 & Germany & 583 & 1832 & 670 \\
\hline 10 & Italy & 398 & 1616 & 644 \\
\hline 11 & Canada & 300 & 1605 & 550 \\
\hline 12 & Iran & 163 & 1056 & 530 \\
\hline 13 & Portugal & 278 & 873 & 516 \\
\hline 14 & Turkey & 187 & 883 & 485 \\
\hline 15 & Taiwan & 319 & 1399 & 421 \\
\hline 16 & Netherlands & 204 & 1064 & 392 \\
\hline 17 & Pakistan & 110 & 397 & 363 \\
\hline 18 & Russia & 524 & 862 & 353 \\
\hline 19 & Romania & 591 & 674 & 326 \\
\hline 20 & Indonesia & 387 & 317 & 320 \\
\hline
\end{tabular}


Table 8 Most influential universities in e-learning ranked by citations

\begin{tabular}{llllll}
\hline Rank & University & Country & Papers & WoS cites & TLS \\
\hline 1 & University of Technology of Sydney & Australia & 19 & 574 & 55 \\
2 & Islamic Azad University & Iran & 43 & 366 & 95 \\
3 & University of Malaya & Malaysia & 43 & 360 & 70 \\
4 & Universidade Nova de Lisboa & Portugal & 21 & 341 & 103 \\
5 & University of Pittsburgh & USA & 29 & 315 & 52 \\
6 & King Abdulaziz University & Saudi Arabia & 52 & 302 & 144 \\
7 & University of Salamanca & Spain & 33 & 296 & 46 \\
8 & Sultan Qaboos University & Oman & 25 & 281 & 63 \\
9 & Beijing Institute of Technology & China & 13 & 273 & 47 \\
10 & King's College London & England (UK) & 29 & 269 & 29 \\
11 & University of Murcia & Spain & 24 & 263 & 32 \\
12 & King Saud University & Saudi Arabia & 30 & 262 & 102 \\
13 & University of Warwick & USA & 21 & 248 & 42 \\
14 & University of Granada & Spain & 48 & 232 & 62 \\
15 & University of Sydney & Australia & 26 & 322 & 31 \\
16 & University of Alcala & Spain & 26 & 231 & 61 \\
17 & University of Copenhagen & Denmark & 19 & 230 & 21 \\
18 & University of British Columbia & Canada & 25 & 228 & 37 \\
19 & National Distance Education University & Spain & 19 & 222 & 44 \\
20 & Vrije Universiteit Amsterdam & Netherlands & 25 & 221 & 62 \\
\hline & & & & & \\
\hline
\end{tabular}

is the second one with 166 keywords. These include e-learning, higher education, university, blended learning, online learning, distance education, lifelong learning, gramification, moodle, MOOC, mobile learning, and cloud computing are predominant. In the third cluster, the blue cluster, with 163 keywords, education, impact, knowledge, internet, attitudes, program, behavior, evaluation, skills, care, quality, simulation, and information, was the most used keywords. And the fourth-largest cluster is the one in yellow, with 118 keywords, model, satisfaction, adoption, acceptance, information technology, user acceptance, user satisfaction, technology acceptance model, perceptions, and success were the most used. In other clusters, the most popular keywords are students, performance motivation, online, higher education, engagement, achievement, Environments, and framework for the purple cluster (97 keywords); technology, augmented reality, virtual reality, innovation, Facebook, innovation, integration, medical education, medical students, platform, social media, undergraduate education, web-based learning for the turquoise cluster (77 keywords); collaboration, distance learning, engineering education, game-based learning, online education, and sciences in the orange cluster (66 keywords); challenges, e-assessment, and expectations in the gray cluster (13 keywords). These findings highlight the importance of e-learning in education or higher education and the importance of using technology in education to improve students' learning experience via the integration of collaboration tools and artificial intelligence. 
Table 9 Most influential universities in e-learning ranked by TLS

\begin{tabular}{|c|c|c|c|c|c|}
\hline Rank & University & Country & Papers & WoS cites & TLS \\
\hline 1 & King Abdulaziz University & Saudi Arabia & 52 & 302 & 144 \\
\hline 2 & King Khalid University & Saudi Arabia & 23 & 87 & 123 \\
\hline 3 & Universidade Nova de Lisboa & Portugal & 21 & 341 & 103 \\
\hline 4 & King Saud University & Saudi Arabia & 30 & 262 & 102 \\
\hline 5 & Islamic Azad University & Iran & 43 & 366 & 95 \\
\hline 6 & University Sains Malaysia & Malaysia & 40 & 178 & 94 \\
\hline 7 & International Islamic University Malaysia & Malaysia & 14 & 48 & 75 \\
\hline 8 & University of Malaya & Malaysia & 43 & 360 & 70 \\
\hline 9 & Sultan Qaboos University & Oman & 25 & 281 & 63 \\
\hline 10 & University of Granada & Spain & 48 & 232 & 62 \\
\hline 11 & Vrije Universiteit Amsterdam & Netherlands & 25 & 221 & 62 \\
\hline 12 & University of Alcala & Spain & 26 & 231 & 61 \\
\hline 13 & University of Technology, Malaysia & Malaysia & 50 & 181 & 61 \\
\hline 14 & University of Lisbon & Portugal & 33 & 117 & 61 \\
\hline 15 & University of Newcastle & Australia & 13 & 121 & 60 \\
\hline 16 & University of Alberta & Canada & 27 & 134 & 59 \\
\hline 17 & Coventry University & England (UK) & 18 & 154 & 58 \\
\hline 18 & Education University of Hong Kong & Hong Kong & 29 & 93 & 58 \\
\hline 19 & Karolinska Institute & Sweden & 30 & 175 & 56 \\
\hline 20 & University of Reading & England (UK) & 10 & 132 & 56 \\
\hline
\end{tabular}

The overlay map that emerged from the keyword co-occurrence analysis reveals the trend over the years, i.e., from 2015 to 2020, and gives an idea about research topics tendency (Goksu, 2021). The overlay visualization map related to our analysis is shown in Fig. 12. Analyzing Fig. 12, we notice that the search topics have almost not changed between 2015 and 2018 since there is a slight color variation. There is a change of research topics between 2017 and 2018, e.g., keywords like medical students, impact, attitudes, students, performance, technology, online, higher education, satisfaction, adoption, user acceptance, and success have been searched. However, it is remarkable that keywords like COVID-19, coronavirus, pandemic, and COVID-19 pandemic have stood out in recent years, i.e., between 2019 and 2020. These results suggest that COVID-19 impacts on e-learning, the reason why the researchers were interested in it between 2019 and 2020. Indeed, this is confirmed by the research of Chaturvedi et al. (2021), Ferrel and Ryan (2020), Marinoni et al. (2020), Dwivedi et al. (2020), and Schleicher (2020).

To explore the impacts of COVID-19 on the students' lives, Chaturvedi et al. (2021) carried out a survey of a total of 1182 people of various age groups from different educational institutions in Delhi, India. The authors' results revealed that COVID-19 has impacts on students' time spent on online courses and self-study, medium used for learning, students' sleep patterns, their daily fitness routine, and subsequent effects on their weight, their social life, and their mental health. With COVID-19's arrival, there is a need for medical researchers to study the pathology and health consequences 


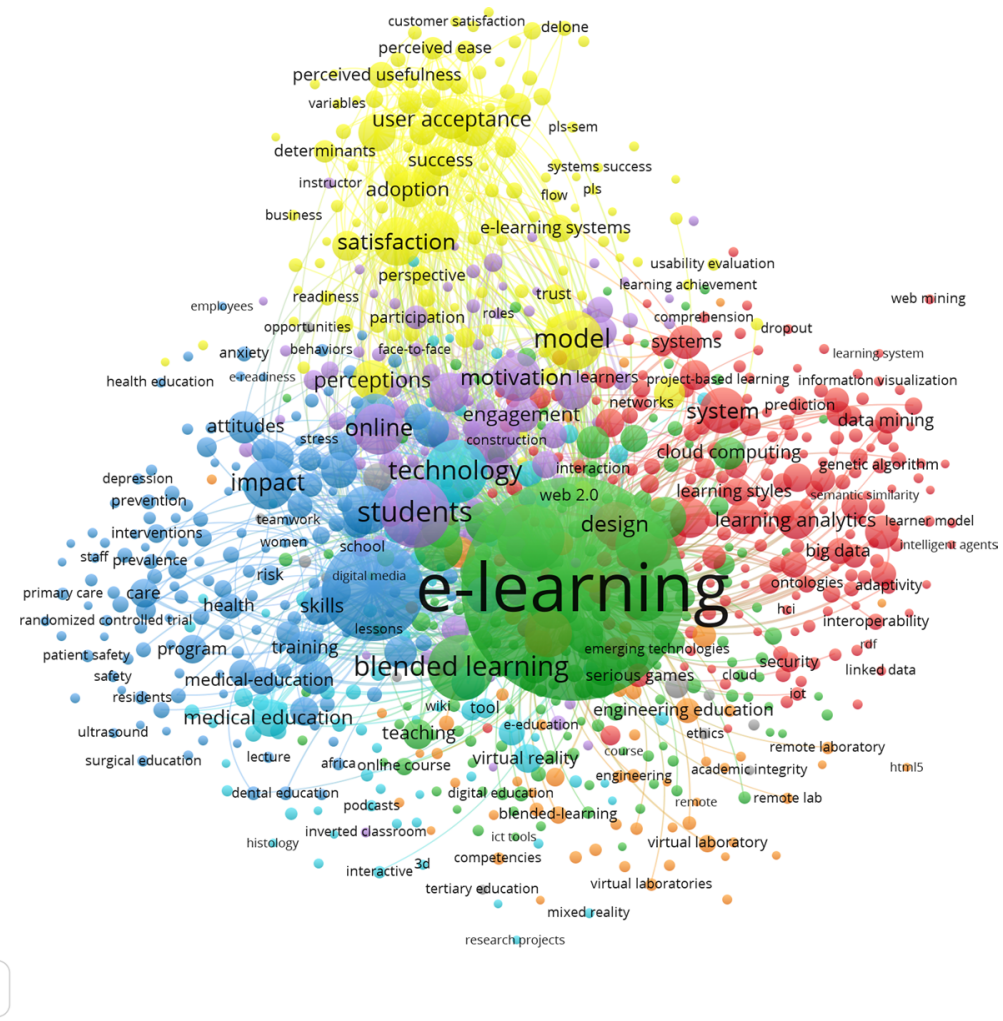

Fig. 11 Network visualization map of keywords' co-occurrence

associated with the virus. Ferrel and Ryan (2020) conducted a study on the impact of COVID-19 on medical education and on the careers of medical practitioners. Their study revealed that the impact of COVID-19 on medical education is currently less clear and as little is known about the long-term impact of COVID-19 on medical education, there is also a need to record and study the full impact of the changes made. Marinoni, Van't Land, and Jensen (2020) analysis 424 full replies from 109 countries in which Africa and Europe are overrepresented, and the Americas and Asia \& Pacific are underrepresented. Their survey shows that almost all the institutions that replied to the survey were impacted by COVID-19, and 59\% of them replied that all campus activities were stopped, and that the institution is completely closed. Research by Dwivedi et al. (2020), and Schleicher (2020) reveals that COVID-19 has a considerable impact on society, and especially on education since its advent.

\section{African contribution}

African countries published 868 papers out of 12272 publications, i.e., $7.0695 \%$ between 2015 and 2020 on e-learning. The countries with the highest number of 


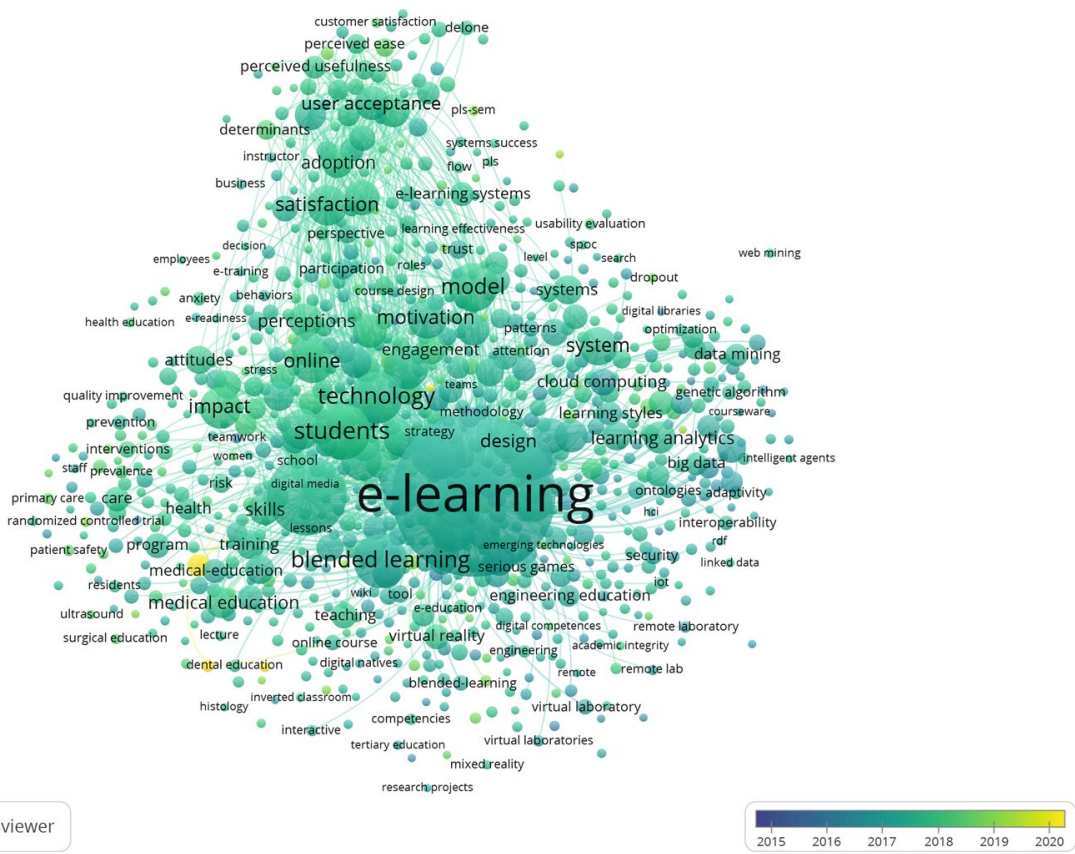

Fig. 12 Overlay visualization map of keywords according to year

published papers are South Africa (228 publications), Morocco (198 publications), Egypt (97 publications), Tunisia (88 publications), Algeria (67 publications), Nigeria (57 publications), Kenya (32 publications), and Ghana (21 publications). The most influential or cited countries are Morocco (cites: 368, TLS:10), South Africa (cites: 217, TLS:30), Egypt (cites: 166, TLS:14), Kenya (cites: 161, TLS:19), and Nigeria (cites: 79, TLS:21). We can state that South Africa, Morocco, and Egypt are the most influential countries by considering the number of publications, citations, and TLS value. We note the presence of Nigeria, and unfortunately the absence of Benin.

Among African universities that have researched on e-learning, the University of South Africa (48 publications), Abdelmalek Essaadi University from Morocco (23 publications), the University of KwaZulu-Nata from South Africa (23 publications), Mohammed V University from Morocco (19 publications), and Covenant University from Nigeria (23 publications) distinguishes themselves with the number of published articles. However, the most cited African universities with more than 5 publications are, Moi University from Kenya (cites: 146, TLS: 0), the University of South Africa (cites: 53, TLS: 3), Helwan university from Egypt (cites: 45, TLS: 0), Abdelmalek Essaadi University from Morocco (cites: 36, TLS: 0), and the University of KwaZulu-Nata from South Africa (cites: 32, TLS: 3). We can observe that the most influential universities come from South Africa and Morocco.

S. Bennani from Mohammed V University has published 11 papers, F. Assalmi from the University of Kairouan has published 11 papers, M. Jemni from the 
University of Tunis has published 11 papers, K. Mansouri from Hassan II University of Casablanca has also published 11 papers, and L. Houghdir from Sidi Mohamed Ben Abdellah University has published 10 papers. The most African cited authors are J. K. Tarus from Moi University (cites: 149, TLS: 7), M. Erritali from Universit Sultan Moulay Slimane (cites: 146, TLS: 8), L. Houghdir from Sidi Mohamed Ben Abdellah University (cites: 28, TLS: 8), A. El Mhouti from Abdelmalek Essaadi University (cites: 25, TLS: 0), and M. Erradi from Mohammed V University (cites: 25, TLS: 0). We note that the majority of the most influential authors come from North Africa or Maghreb countries. And we also note a total absence of authors coming from sub-Saharan Africa.

\section{Discussions and conclusion}

We performed the analysis on 12,272 publications on e-learning between 2015 and 2020, which represents $0.06466 \%$ of the research conducted between 2015 and 2020 on e-learning published in WoS, i.e., 12,272 of 18,976,811. We first performed a quantitative analysis of the metadata to determine the output by years, universities, countries, authors, journals, and research areas.

Countries such as Spain, the USA, England, China, and Romania produced more publications. By doing qualitative analysis, the most cited countries are the USA, followed by Spain, England, Australia, and China. A comparison of these results shows that although Romania is among the countries that have published more papers, it is not among the most influential countries (see Table 6). However, we found that Australia is among the top 5 most influential countries, but is not among the top 5 countries that have produced many papers (see Fig. 2).

The University Politehnica of Bucharest, the University of Hradec Kralove, the University of Hong Kong, King Abdulaziz University, and the Complutense University of Madrid are the universities with significant production (see Fig. 6). However, the University of Technology of Sydney, Islamic Azad University, the University of Malaya, Universidade Nova de Lisboa, and the University of Pittsburgh are the most cited universities (see Table 8). We notice that universities with more papers are not the most cited ones. Considering the TLS value, the influential universities are Islamic Azad University, Universidade Nova de Lisboa, and King Abdulaziz University.

Regarding the authors, C. Radu, M. Virvou, S. Lujan-Mora, C. Meinel, and I. Simonova are the authors with the most publications in the field. Unfortunately, they not the most cited; among those most cited, we have A. Tarhini, M. Aparicio, T. Oliveira, K. J. Tarus, and Z. Niu. It is not the number of publications from one country or university or author that makes it the most influential entity in the field. It is possible to produce enough documents, but if the documents are not relevant enough for the scientific community, it will be less cited, therefore less known and cited, consequently less influential. To be a reference in a research field, the quantity does not necessarily matter, but rather the quality of the work, especially the community that can read and evaluate the work. That is why it is necessary to find a journal recognized in the field to submit your work. 
The most influential researchers in e-learning are generally those working in universities from the UK, the USA, and China. We noticed that the most cited authors do not write the most cited papers and do not come from the most influential countries or universities. This result shows that a research publication can be important in a field regardless of the author's origin or university or country. The second observation is that the collaboration between researchers working on e-learning is weak even though there are enough authors. The main collaborations are with developed countries like England, the USA, Spain, Italy, Germany, Australia, China, Netherlands, France, Canada, Portugal, and Belgium. Developing countries are currently lagging in educational technology, especially African countries.

The co-occurrence analysis highlights the importance of e-learning in education or higher education, and the relevance of using technology in education to enhance the student learning experience via collaboration tools and artificial intelligence. Reasons why journals like Computers in Human Behavior, Computers \& Education, International Journal of Emerging Technologies in Learning, BMC Medical Education, and British Journal of Educational Technology are the most influential in e-learning in recent years. The co-occurrence analysis also revealed that very few researches deal with security or data protection in e-learning environments. When searching for security-related keywords in e-learning publications between 2015 and 2020, we got very few hits, for example, "academic integrity" (occurrence: 12, TLS: 44), "authentication" (occurrence: 15, TLS: 33), "confidence" (occurrence: 17, TLS: 42), "policy" (occurrence: 14, TLS: 53), "privacy" (occurrence: 18, TLS: 59), "risk" (occurrence: 51, TLS: 191), "risk management" (occurrence: 13, TLS: 33), "safety" (occurrence: 17, TLS: 88), and "security" (occurrence: 50, TLS: 132). These findings show that there is very little research on security in recent years.

Despite the absence of African countries on the worldwide level in the e-learning research area, African contribution analysis revealed the presence of South Africa, Kenya, and the majority of the Maghreb countries. We observed an absence of subSaharan countries, especially almost all francophone countries. The most influential universities and authors in Africa come from the Maghreb countries and South Africa. Despite the limited presence of African countries, the collaboration between these countries is very weak compared to their collaborations with developed countries. This can be explained by the fact that developed countries or influential countries offer their collaboration or funding to African countries. Efforts should be made among African countries to promote collaborative work in order to strengthen their position on the international scene.

This study has limitations. First, we only used WoS to collect the data, and it does not include all academic publications such as Scopus. Second, the latest publications (2020 publications) that were accepted but not indexed in WoS were ignored. Nevertheless, such limitations are unlikely to affect the results identified in this study. Furthermore, in the data search, we only used the term "e-learning" as search terms, while terms such as "online learning," "distance learning," and others can be used to extend the search scope. Although the use of synonymous search terms may lead to a more accurate dataset on the topic, the results obtained showed that our dataset retrieved from WoS is acceptable as all major aspects in e-learning are covered. 
This study revealed that in recent years, research on security or data protection in e-learning has been relatively low compared to other research topics in the area. Is the security in e-learning not important? Are there security risks in e-learning environments? Or is learners' privacy not a concern? Our future work will be a literature review or an overview on data security in e-learning.

Acknowledgements This publication was made possible through the DSTN supported by IRD and AFD. We would like to thank the African Center of Excellence in Mathematical Science, Informatics, and Applications (CEA-SMIA) and the African Centre of Excellence on Technology Enhanced Learning (ACETEL) for their support.

\section{References}

Alajmi, Q., Al-Sharafi, M. A., \& Abuali, A. (2020). Smart learning gateways for Omani HEIs towards educational technology: Benefits, challenges and solutions. International Journal of Information Technology, 4(1), 12-17.

Birkle, C., Pendlebury, D. A., Schnell, J., \& Adams, J. (2020). Web of Science as a data source for research on scientific and scholarly activity. Quantitative Science Studies, 1(1), 363-376.

Chaturvedi, K., Vishwakarma, D. K., \& Singh, N. (2021). COVID-19 and its impact on education, social life and mental health of students: A survey. Children Youth Services Review, 121, 105866.

Chen, X., Yu, G., Cheng, G., \& Hao, T. (2019). Research topics, author profiles, and collaboration networks in the top-ranked journal on educational technology over the past 40 years: A bibliometric analysis. Journal of Computers in Education, 6(4), 563-585.

Chen, X., Zou, D., \& Xie, H. (2020a). Fifty years of British Journal of Educational Technology: A topic modeling based bibliometric perspective. British Journal of Educational Technology, 51(3), 692-708.

Chen, X., Zou, D., Xie, H., \& Wang, F. L. (2020b). Smart learning environments: A bibliometric analysis. International Conference on Blended Learning, 1, 353-364.

Chen, X., Zou, D., Xie, H., \& Wang, F. L. (2021). Past, present, and future of smart learning: A topicbased bibliometric analysis. International Journal of Educational Technology in Higher Education, 18(1), 1-29.

Cheng, B., Wang, M., Mørch, A. I., Chen, N.-S., Spector, J. M., et al. (2014). Research on e-learning in the workplace 2000-2012: A bibliometric analysis of the literature. Educational Research Review, $11,56-72$.

Deng, S., \& Xia, S. (2020). Mapping the interdisciplinarity in information behavior research: A quantitative study using diversity measure and co-occurrence analysis. Scientometrics, 124(1), 489-513.

Dhawan, S. (2020). Online learning: A panacea in the time of COVID-19 crisis. Journal of Educational Technology Systems, 49(1), 5-22.

Dwivedi, Y. K., Hughes, D. L., Coombs, C., Constantiou, I., Duan, Y., Edwards, J. S., Gupta, B., Lal, B., Misra, S., Prashant, P., \& Raman, R. (2020). Impact of COVID-19 pandemic on information management research and practice: Transforming education, work and life. International Journal of Information Management, 55, 102211.

Ferrel, M. N., \& Ryan, J. J. (2020). The impact of COVID-19 on medical education. Cureus, 12(3), 7439.

Goksu, I. (2021). Bibliometric mapping of mobile learning. Telematics and Informatics, 56, 101491.

Hoq, M. Z. (2020). E-Learning during the period of pandemic (COVID-19) in the kingdom of Saudi Arabia: An empirical study. American Journal of Educational Research, 8(7), 457-464.

Huynh, V. D. B., Nguyen, P. T., Nguyen, Q., \& Vu, N. B. (2020). E-learning evolution and development from the perspectives of technology, education, and economy. Research in World Economy, 11(1), 11-19.

Kumar Basak, S., Wotto, M., \& Belanger, P. (2018). E-learning, M-learning and D-learning: Conceptual definition and comparative analysis. E-Learning and Digital Media, 15(4), 191-216.

Lai, C.-L. (2020). Trends of mobile learning: A review of the top 100 highly cited papers. British Journal of Educational Technology, 51(3), 721-742. 
Marinoni, G., Van't Land, H., \& Jensen, T. (2020). The impact of Covid-19 on higher education around the world. IAU Global Survey Report.

Moore, J. L., Dickson-Deane, C., \& Galyen, K. (2011). e-Learning, online learning, and distance learning environments: Are they the same? The Internet and Higher Education, 14(2), 129-135.

Schleicher, A. (2020). The impact of covid-19 on education insights from education at a glance 2020. Retrieved from https://www.oecd.org/education/the-impact-of-covid-19-on-education-insightseducation-at-a-glance-2020.pdf.

Song, Y., Chen, X., Hao, T., Liu, Z., \& Lan, Z. (2019). Exploring two decades of research on classroom dialogue by using bibliometric analysis. Computers \&amp; Education, 137, 12-31.

Tibaná-Herrera, G., Fernández-Bajón, M. T., \& de Moya-Anegón, F. (2018a). Global analysis of the E-learning scientific domain: A declining category? Scientometrics, 114(2), 675-685.

Tibaná-Herrera, G., Fernández-Bajón, M.-T., \& De-Moya-Anegón, F. (2018b). Output, collaboration and impact of e-learning research: Bibliometric analysis and visualizations at the country and institutional level (Scopus 2003-2016). El Profesional De La Información (EPI), 27(5), 1082-1096.

Publisher's Note Springer Nature remains neutral with regard to jurisdictional claims in published maps and institutional affiliations.

Essohanam Djeki is a first year Ph.D. student in Information and Communication Technology (ICT) at the Institute of Mathematics and Physics (IMSP) of University of Abomey-Calavi, Benin. He graduated from IMSP in 2020 with a Master's degree in ICT. He is interested in personal data protection and privacy in digital learning spaces. His previous work focused on security in the cloud. He is currently studying the impact of COVID-19 on e-learning in Africa, opportunities and challenges of e-learning for sub-Saharan countries, security risks in digital learning environments, and mechanisms to ensure privacy protection for online learners. His objective is to propose a solution adapted to African contexts.

Jules Dégila (Ph.D.) is a Senior Lecturer in Computer Science at the University of Abomey-Calavi, Benin. His research interest includes Networks and systems optimization, the Internet of things, Blockchain and inclusive ICT. He has led the Operations Research and Computer Science department at the Institute of Mathematics and Physics (IMSP). He has held different management, executive, and board member positions for Western and African telecommunications companies during the last ten years. A guest speaker at various universities for technologies vulgarization, he has also advised many companies and governments as a strategist in real-time communications and internet protocol (IP) networking. Jules received a Ph.D. degree in electrical engineering from École Polytechnique de Montréal, Canada in 2004.

Carlyna Bondiombouy is a big data consultant at Ysance, Paris. Previously, she was a doctoral researcher at Inria in the Zenith Inria team, Montpellier, pursuing research on big data integration and polystore systems. She obtained her Ph.D. degree from the University of Montpellier in 2017, a Master's degree from Cheikh Anta Diop University, Dakar (Senegal) in 2013, and a B.Sc. degree from IAI Libreville (Gabon) in 2010. She published several papers in international conferences and journals on big data, databases and cloud computing. In addition, she was awarded the best $\mathrm{Ph}$.D. thesis among fellow students of the Congo government in 2017.

Muhtar Hanif Alhassan (Ph.D.) is Professor in Computer Science at National Open University of Nigeria (NOUN), Nigeria. He has been Deputy Vice Chancellor, Head of Department and Senior Lecturer at Nile University of Nigeria. He has held the Management Information Systems at NOUN. He obtained MBA in Technology Management from ATB University, Bauchi in 2001, a Ph.D. degree from the University of Sussex, Brighton, UK in 1993, a M.Sc. degree in Industrial Automation from Belarus Polytechnic Institute, Minsk (1977-1982), and A-Level Certificate in Mathematics, Physics and Chemistry from Kiev State University, Kiev Ukraine in 1975. His research interest includes Industrial Automation, Computer Control, Technology Management and Cyber Security. 